\title{
The Goal of Achieving Atherosclerotic Plaque Regression with Lipid-Lowering Therapy: Insights from IVUS Trials
}

\author{
Hiroyuki Daida, Tomotaka Dohi, Yoshifumi Fukushima, Hirotoshi Ohmura and Katsumi Miyauchi
}

Department of Cardiovascular Medicine, Juntendo University Graduate School of Medicine, Tokyo, Japan

Enormous effort has been put into the prevention of atherosclerosis through risk modification, especially with lipid-lowering therapies. Regression, that is, the reversal of the atherosclerosis process, has long been a goal of atherosclerosis research among basic and clinical investigators. Intravascular ultrasound (IVUS) was developed in the 1990s as an intracoronary imaging technique to observe the details of the vessel walls and to measure the vessel lumen and plaque area with high reproducibility. Compared with the coronary angiogram, IVUS provides far more detailed information on the vessel wall. In this article, we review lipid-lowering trials that have used IVUS and discuss the current understanding of the effectiveness of aggressive lipid-lowering therapy, which inhibits atherosclerotic progression and induces regression and plaque stabilization.

Key words: Lipid-lowering therapy, LDL-C, Plaque regression, IVUS, Statin

\section{Introduction}

Atherosclerosis has been classified as the biggest health-care issue around the world ${ }^{1)}$. Indeed, global health statistics have shown that atherosclerotic cardiovascular disease is the leading cause of death worldwide, and its incidence is increasing in developing countries $^{2,3)}$. Enormous effort has been put into the prevention of atherosclerosis through risk modification, especially with lipid-lowering therapies ${ }^{4-6)}$. Regression, that is, the reversal of the atherosclerosis process, has long been a goal of atherosclerosis research among basic and clinical investigators. Substantial effort has been made on plaque regression under lipidlowering therapy and is still ongoing ${ }^{7}$.

In this article, we review lipid-lowering trials that have used intravascular ultrasound (IVUS) and discuss the current understanding of the effectiveness of aggressive lipid-lowering therapy, which inhibits atherosclerotic progression and induces regression and plaque stabilization.

\section{Mechanism of Atherosclerosis Reversal and Regression}

The regression of atherosclerosis by lowering lipid levels has been a hypothetical goal of therapy since the early 1900s. Several experimental studies have suggested the possibility of plaque regression by showing reduced plaque area with a change from a high-cholesterol to a low-cholesterol diet in animal models ${ }^{8,9)}$. Brown et al. reported that the improvement of the plaque lipoprotein environment can rapidly correct the macrophage content by reducing the numbers of intraplaque macrophages and forming cells, down-regulating the expression of inflammatory markers and inducing the enrichment with antiinflammatory markers ${ }^{10}$.

Lesion regression is accompanied by potent improvements in the plaque microenvironment, particularly by a strong decrease in plasma levels of apoBcontaining lipoproteins and a marked increase in lipid efflux from the plaque ${ }^{11)}$. Plaque shrinkage is a coordinated process that involves the depletion of foam cells and extracellular cholesterol stores, a gradual decline in macrophage numbers through enhanced emigration from the plaque, and the replacement of inflammatory macrophages with anti-inflammatory phagocytes, involved in the removal of necrotic material and tissue healing (Fig. 1).

Consequently, good results of clinical studies using lipid-lowering agents, such as statins, can be

Address for correspondence: Hiroyuki Daida, Department of Cardiovascular Medicine, Juntendo University Graduate School of Medicine, 2-1-1 Hongo, Bunkyoku, Tokyo 113-0033, Japan E-mail: daida@juntendo.ac.jp

Received: January 9, 2019 Accepted for publication: April 16, 2019

Copyright@2019 Japan Atherosclerosis Society

This article is distributed under the terms of the latest version of CC BY-NC-SA defined by the Creative Commons Attribution License. 
LUMEN

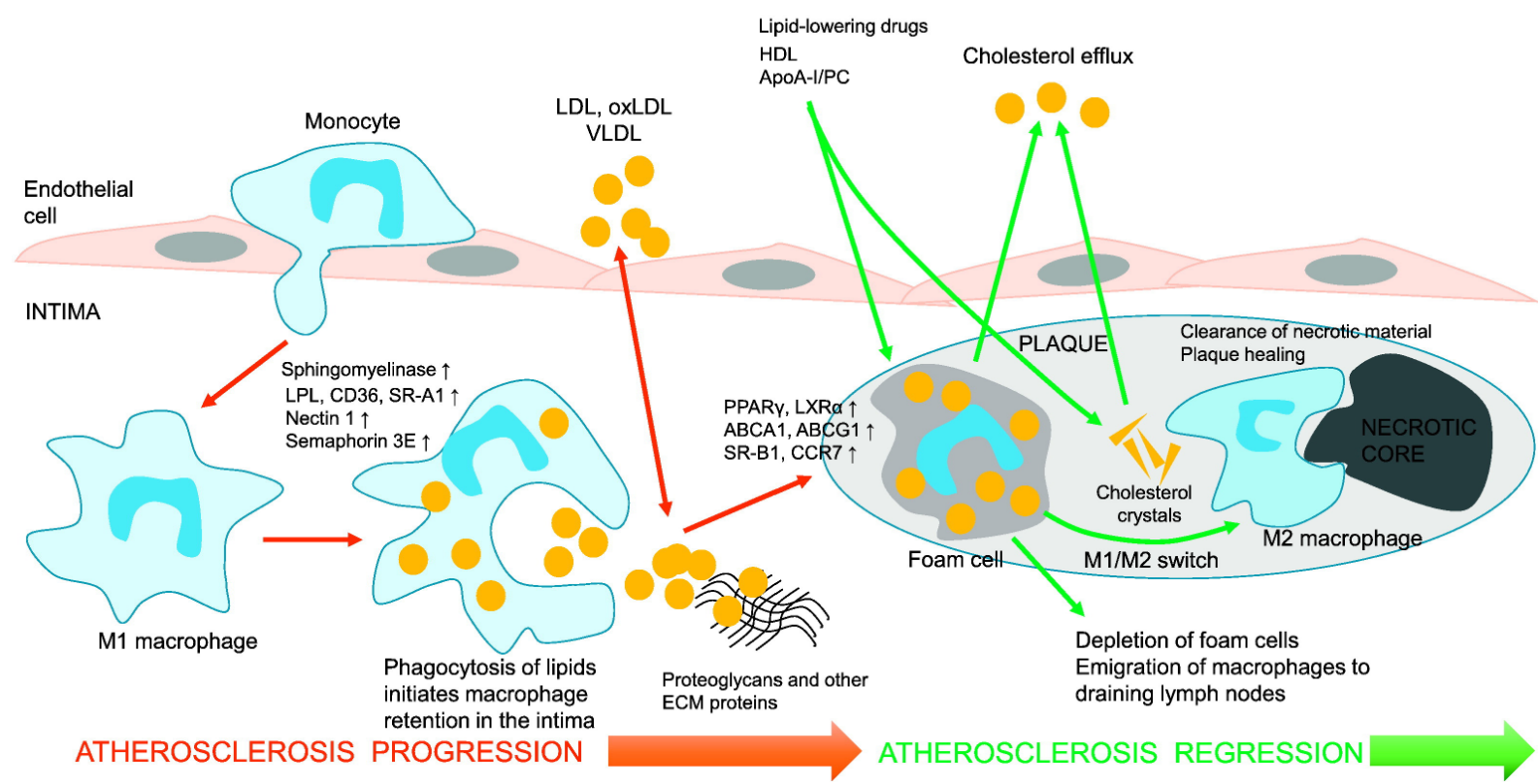

Fig. 1. Atherosclerosis progression and reversal by enhancing cholesterol efflux and emigration of macrophages from the plaque

The proinflammatory recruitment of monocytes is followed by their subendothelial trafficking to the arterial intima, where monocytes differentiate into proinflammatory macrophages. The macrophages phagocytize proatherogenic low-density lipoprotein (LDL), oxidized LDL (oxLDL), and very low-density lipoprotein enriched with cholesterol. The accumulation of lipids in macrophages leads to their loss of mobility, retention in the vascular wall, and transformation to foam cells. Foam cells contribute to the formation of the intraplaque lipid pool and then the necrotic core. The increased production of matrix metalloproteinases (MMPs) by foam cells and plaque macrophages leads to plaque destabilization and rupture. Potent improvements in plasma lipoprotein levels by lowering LDL cholesterol and increasing high-density lipoprotein cholesterol can induce plaque regression, characterized by the enhancement of the reverse cholesterol transport, reduction of foam cell numbers, macrophage emigration, and phenotypic switch of retained macrophages from proinflammatory cells to anti-inflammatory cells that deal with the clearance of necrotic debris and plaque material and tissue repair. The increased mobility of macrophages is associated with up-regulation of liver X receptor and peroxisome proliferator-activated receptor gamma (PPAR $y$ ), which mediate cholesterol efflux in macrophages, activation of anti-inflammatory genes and cell mobility genes such as C-C chemokine receptor 7 (CCR7), and down-regulation of genes that inhibit cell migration such as semaphore in $3 \mathrm{E}$ and netrin 1.

Abbreviations: ABCA1, ATP-binding cassette transporter A1; ECM, extracellular matrix; LPL, lipoprotein lipase; PC, phosphatidylcholine; SR-B1, scavenger receptor.

Reprinted from "The phenomenon of atherosclerosis reversal and regression": Lessons from animal models, Experimental and Molecular Pathology 102 (2017) 138-145. Copyright (2017), with permission from Elsevier “48

attributed primarily to the induction of stability of small vulnerable plaques by reducing intraplaque macrophage numbers, an important signature of lesion vulnerability ${ }^{12}$. These plaques contain a large lipid core and dense clusters of intimal macrophages. Such lesions constitute only $10-20 \%$ of the entire plaque population, but account for $80-90 \%$ of acute clinical events.

\section{History of Atherosclerosis Regression Studies and Development of IVUS}

Epidemiologists and pathologists recognized less severe atherosclerosis in the aorta or coronary arteries in subjects with malnutrition or emaciation during
World Wars I and II, suggesting that dietary modification could reduce the progression of atherosclerosis ${ }^{13)}$. Angiographic trials were enthusiastically conducted from 1980 to 2000, and the overall results indicated that the aggressive modification of lipid profiles could inhibit plaque progression and induce some degree of regression ${ }^{14-17)}$. The introduction of IVUS further stimulated research into the progression and regression of atherosclerosis. This modality enabled us to observe and measure atherosclerotic plaques quantitatively as well as qualitatively ${ }^{18)}$.

IVUS was developed in the 1990s as an intracoronary imaging technique to observe the details of the vessel walls and to measure the vessel lumen and plaque area with high reproducibility ${ }^{18)}$. Compared 
with the coronary angiogram, IVUS provides far more detailed information on the vessel wall, including the size and location of atheromatous plaques, plaque tissue characteristics, and vessel remodeling. After the introduction of the auto-pullback system, IVUS took its place as the principal imaging tool in atherosclerotic progression/regression trials instead of the quantitative coronary angiogram, because of its ability to precisely measure plaque volume and also provide quantitative measurements of plaque morphology and tissue characteristics ${ }^{19,20)}$.

\section{Aggressive LDL-C Lowering for Plaque Regression in Patients with Coronary Artery Disease; IVUS Trials}

The first IVUS trial in the field of atherosclerotic progression/regression was reported from Kobe, Japan, using pravastatin. Takagi et al. found a significant inhibition of atherosclerotic progression, although they only investigated the cross-sectional area of target lesions ${ }^{21}$. In 2002, Matsuzaki et al. found a significant inhibition and slight regression of atherosclerotic plaques using LDL apheresis in patients with heterozygous familial hypercholesterolemia ${ }^{22)}$. They also measured the cross-sectional areas of targeted plaques in their trial. The very first trial with the application of volumetric analysis was the German Atorvastatin Intravascular Ultrasound Study (GAIN) trial in which the investigators measured plaque volume as well as plaque characteristics with gray-scale IVUS. Although they could not identify any significant regression of plaques, they did find increased plaque intensity on gray-scale IVUS ${ }^{23)}$. The landmark study in this field is Reversal of Atherosclerosis with Aggressive Lipid Lowering (REVERSAL) ${ }^{24)}$. In this trial, Nissen et al. compared changes in plaque volume between $40 \mathrm{mg}$ of pravastatin and $80 \mathrm{mg}$ of atorvastatin in patients with chronic coronary artery disease and found a small but significant rate of progression in the pravastatin group, but no progression in the atorvastatin group at the LDL-C level of $80 \mathrm{mg} / \mathrm{dL}$. A Study to Evaluate the Effect of Rosuvastatin on Intravascular UltrasoundDerived Coronary Atheroma Burden (ASTEROID) demonstrated significant plaque regression in patients with stable coronary artery disease using rosuvastatin at the LDL-C level of $53 \mathrm{mg} / \mathrm{dL}^{25}$.

The ESTABLISH (Early statin treatment in patients with acute coronary syndrome: demonstration of the beneficial effect on atherosclerotic lesions by serial volumetric intravascular ultrasound analysis during half a year after coronary event) study investigated the efficacy of early, aggressive statin therapy in patients with acute coronary syndrome (ACS) ${ }^{26)}$.
Early, aggressive lipid-lowering therapy with $20 \mathrm{mg}$ of atorvastatin for 6 months significantly reduced the plaque volume by $13 \%$ at an LDL-C level of $70 \mathrm{mg} /$ $\mathrm{dL}$ in patients with ACS. The percentage change in plaque volume showed a significant positive correlation with percentage reduction in LDL-C, even in patients with low baseline levels of LDL-C.

Since these early trials in the field of atherosclerosis research, a substantial number of clinical trials using IVUS have been conducted all over the world in patients with chronic coronary disease and ACS ${ }^{27-29)}$. The observations have been consistent in finding that aggressive lipid modification could reduce atherosclerotic progression and induce plaque regression. In addition, the degree of plaque change was associated with the LDL-C level or the percentage reduction in LDL-C. These changes are more obvious among patients with ACS who have more unstable plaques that appear to be more prone to regress with aggressive LDL-C lowering ${ }^{7)}$. In the PRECISE-IVUS (Plaque REgression With Cholesterol Absorption Inhibitor or Synthesis Inhibitor Evaluated by IntraVascular UltraSound) trial, Tsujita et al. demonstrated a further reduction in plaque volume using ezetimibe in addition to statin, and confirmed the effectiveness of aggressive LDL-C-lowering therapy among the Japanese population ${ }^{30}$. They also found a larger response in patients with ACS than in those with stable coronary artery disease. The most recent IVUS trial, GRAGOV (Global Assessment of Plaque Regression With a PCSK9 Antibody as Measured by Intravascular Ultrasound), reported the effectiveness of the PCSK9 inhibitor compared with statin alone, on plaque regression at the LDL-C level of $36 \mathrm{mg} / \mathrm{dL}$, further confirming "the lower the better" theory ${ }^{31)}$ (Table 1).

\section{IVUS Trials Demonstrating Plaque Stabilization by Lipid Lowering}

During the process of plaque regression by aggressive lipid-lowering therapy, treatment could also stabilize the unstable plaque and reverse the positive remodeling of the vessel wall. An unstable plaque was characterized by a thin fibrous cap, a large lipid core, and inflammatory cell infiltration ${ }^{32)}$. An unstable plaque is observed frequently in vessel segments with positive remodeling. Lipid-lowering therapy could change these characteristics to thicken the fibrous cap, reduce the lipid core, and decrease inflammatory cell infiltration ${ }^{33,34)}$. This represents a reversal of the process of positive remodeling of the vessel wall.

Changes in these plaque characteristics were also identified in IVUS trials. As described previously, the GAIN trial first reported changes in plaque character- 
Table 1. Serial intravascular ultrasound studies of plaque progression/regression

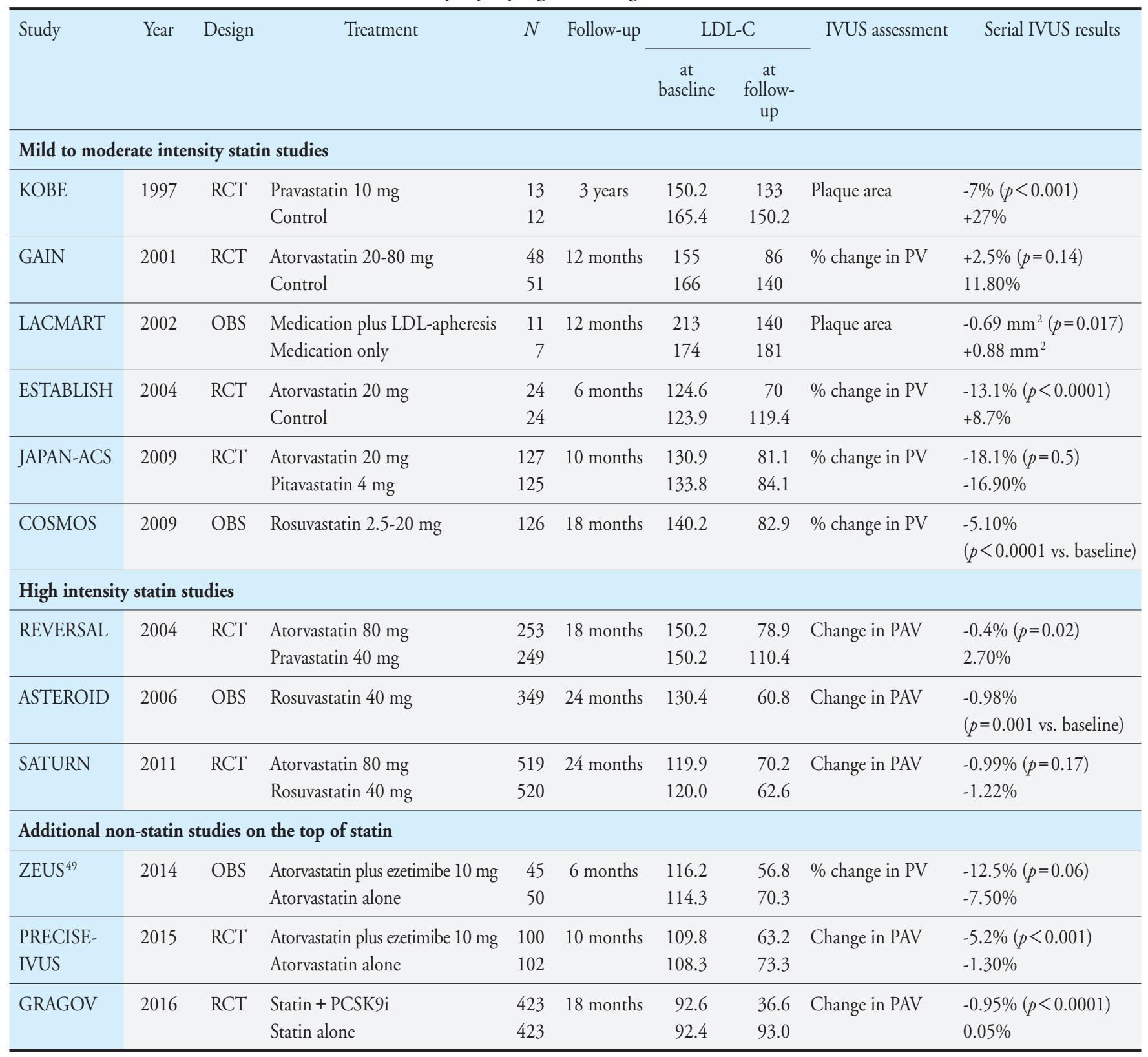

RCT: randomized controlled trial; OBS: observational study: PV: plaque volume; PAV: percent atheroma volume; IVUS: intravascular ultrasound

istics using gray-scale IVUS ${ }^{23)}$. In early 2000, several IVUS systems were developed to investigate plaque characteristics. Kawasaki et al. demonstrated a significant reduction in the lipid composition of plaque in the statin-treated group compared with controls using an integrated backscatter-IVUS system ${ }^{35)}$. Nasu et al. also reported a significant reduction of fibro-fatty tissue by fluvastatin, with plaque volume reduction, using virtual histology (VH)-IVUS ${ }^{36)}$. Park et al. recently reported that rosuvastatin treatment could change plaque composition and plaque volume in non-culprit coronary lesions estimated by $\mathrm{VH}$ IVUS ${ }^{37)}$. Overall results from tissue IVUS trials have revealed that aggressive LDL-C lowering could reduce the lipid composition with or without reductions in plaque volume ${ }^{38-43)}$. The positive remodeling of the vessel wall is also reduced by aggressive LDL-C lowering, appearing as a shrinkage of vessel size. These changes appear to correlate with the degree of LDL-C reduction, further strengthening "the lower the better" theory from this perspective (Table 2). 
Table 2. Serial intravascular ultrasound studies of plaque composition

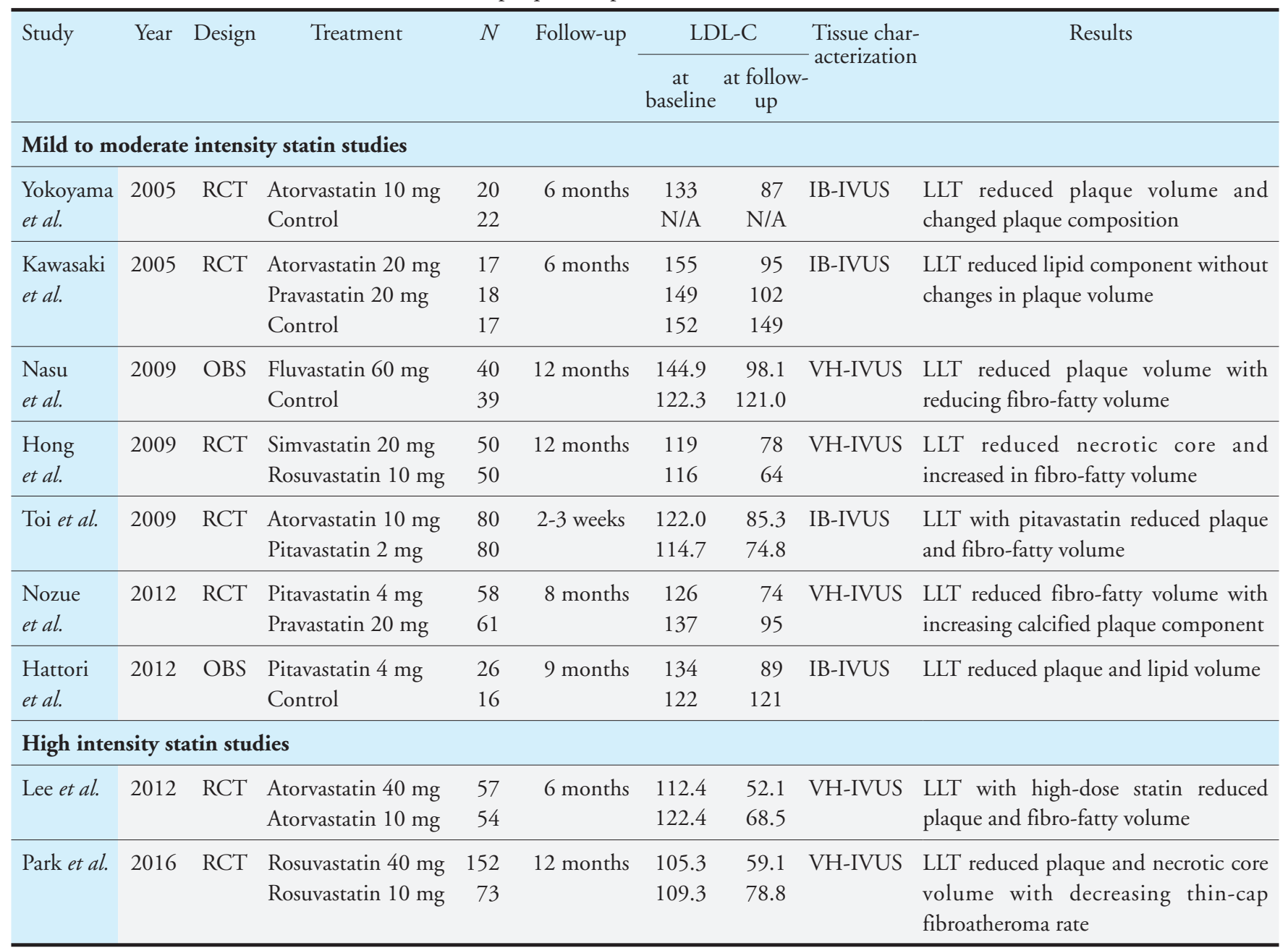

RCT: randomized controlled trial; OBS: observational study: IB-IVUS: integrated backscatter intravascular ultrasound; VH-IVUS; virtual histology intravascular ultrasound; LLT: lipid-lowering therapy

\section{Clinical Significance of Plaque Regression}

Whether plaque volume changes could predict future events has been a matter of considerable discussion. Nissen et al. found a significantly higher event rate among patients with plaque progression than among patients with plaque regression in their IVUS trials ${ }^{44}$. Dohi et al. also found significantly better outcomes in patients with plaque regression than in patients with progression in the Extended ESTABLISH trial after 4 years of follow-up ${ }^{45}$. Although several plaque imaging modalities could not predict clinical outcomes, coronary artery imaging modalities have consistently been reported to offer a sufficient and powerful tool for predicting future clinical events among patients with coronary artery disease.

\section{Summary and Future Directions}

The regression of atherosclerosis through lipid lowering has been a goal since the early 1900s. Early experimental and epidemiological studies suggested the possibility of plaque regression. Angiographic trials were conducted from 1980 to 2000 and their overall results indicated that aggressive modification of the lipid profile could inhibit plaque progression and induce some degree of regression. The introduction of IVUS further stimulated research into the progression and regression of atherosclerosis. This modality enabled us to observe and measure atherosclerotic plaques quantitatively as well as qualitatively. Observations have been consistent in suggesting that aggressive lipid profile modification could reduce atherosclerotic progression and induce plaque regression.

In addition, the degree of plaque change was 
associated with the level of LDL-C or the percentage reduction in LDL-C. Notably, the LDL-C threshold of $70 \mathrm{mg} / \mathrm{dL}$, which recurs in Japanese, European, and American recommendations, is close to the theoretical inversion point from a condition of coronary atherosclerosis progression to one of regression ${ }^{25}$. Furthermore, no threshold level below which the LDL-C lowering benefit ceases has been established, and in the IMPROVE-IT (IMProved Reduction of Outcomes: Vytorin Efficacy International Trial) and the FOURIER (Further Cardiovascular Outcomes Research With PCSK9 Inhibition in Patients With Elevated Risk) trials, additional benefits from ezetimibe and evolocumab were found, regardless of LDL-C levels ${ }^{46,47}$. The process of plaque regression by aggressive LDL-C lowering therapy could also stabilize the unstable plaque and reverse the positive remodeling of the vessel wall. The pharmacological inhibition of cholesterol absorption (with ezetimibe) and PCSK9 activity (with evolocumab or alirocumab) provides potentially useful approaches for the therapeutic modulation of LDL-C metabolism in statin-treated patients. As combination therapy with a statin and either ezetimibe or PCSK9 inhibitors lowers LDL-C levels beyond that achieved with statin monotherapy, this early dual lipid-lowering treatment strategy may have additional protective cardiovascular effects, reducing coronary disease progression and improving cardiovascular outcomes in selected patients.

The observations available from IVUS appear to offer a powerful tool for predicting future clinical events among patients with coronary artery disease. More recently, other coronary imaging modalities have come into clinical use, such as optical coherence tomography and near-infrared spectroscopy, further accelerating research into atherosclerotic progression and regression, improving our understanding of the mechanisms underpinning atherosclerosis, and opening up new treatment options.

\section{Funding}

None.

\section{COI}

The authors report the following disclosures: $\mathrm{H}$. Daida has received honoraria from Amgen Astellas Biopharma , Astellas Pharma, AstraZeneca, GlaxoSmithKline, Sanofi, Daiichi Sankyo, Takeda Pharmaceutical, Medtronic Japan, Bayer, and MSD, and clinical research funding from KAKEN PHARMACEUTICAL, Kowa Company, Daiichi Sankyo, Abbott Vascular Japan, and Nihon Medi-Physics PPD, and scholarship grant from Astellas Pharma, Abbott Vascular Japan, Sanofi, Daiichi Sankyo, Bayer, Public Health Research Foundation and Pfizer; T. Dohi has received honoraria from Sanofi; $\mathrm{H}$. Ohmura has received honoraria from Amgen Astellas Biopharma ; K. Miyauchi has received honoraria from Amgen Astellas Biopharma, Astellas Pharma, Sanofi, Daiichi Sankyo, Takeda Pharmaceutical, Bayer, Boehringeringelheim and MSD; none of the other authors has any potential conflicts of interest to disclose.

\section{References}

1) Writing Group M, Mozaffarian D, Benjamin EJ, Go AS, Arnett DK, Blaha MJ, Cushman M, Das SR, de Ferranti S, Despres JP, Fullerton HJ, Howard VJ, Huffman MD, Isasi CR, Jimenez MC, Judd SE, Kissela BM, Lichtman JH, Lisabeth LD, Liu S, Mackey RH, Magid DJ, McGuire DK, Mohler ER, 3rd, Moy CS, Muntner P, Mussolino ME, Nasir K, Neumar RW, Nichol G, Palaniappan L, Pandey DK, Reeves MJ, Rodriguez CJ, Rosamond W, Sorlie PD, Stein J, Towfighi A, Turan TN, Virani SS, Woo D, Yeh RW, Turner MB, American Heart Association Statistics C and Stroke Statistics S: Heart Disease and Stroke Statistics-2016 Update: A Report From the American Heart Association. Circulation, 2016; 133: e38-360

2) Gaziano TA, Bitton A, Anand S, Abrahams-Gessel $S$ and Murphy A: Growing epidemic of coronary heart disease in low- and middle-income countries. Curr Probl Cardiol, 2010; 35: 72-115

3) Mathers CD and Loncar D: Projections of global mortality and burden of disease from 2002 to 2030. PLoS Med, 2006; 3: e442

4) Ference BA, Ginsberg HN, Graham I, Ray KK, Packard CJ, Bruckert E, Hegele RA, Krauss RM, Raal FJ, Schunkert H, Watts GF, Boren J, Fazio S, Horton JD, Masana L, Nicholls SJ, Nordestgaard BG, van de Sluis B, Taskinen MR, Tokgozoglu L, Landmesser U, Laufs U, Wiklund O, Stock JK, Chapman MJ and Catapano AL: Low-density lipoproteins cause atherosclerotic cardiovascular disease. 1. Evidence from genetic, epidemiologic, and clinical studies. A consensus statement from the European Atherosclerosis Society Consensus Panel. Eur Heart J, 2017; 38: 2459-2472

5) Esrey KL, Joseph L and Grover SA: Relationship between dietary intake and coronary heart disease mortality: lipid research clinics prevalence follow-up study. J Clin Epidemiol, 1996; 49: 211-216

6) Buchwald H, Varco RL, Matts JP, Long JM, Fitch LL, Campbell GS, Pearce MB, Yellin AE, Edmiston WA, Smink RD, Jr. and et al.: Effect of partial ileal bypass surgery on mortality and morbidity from coronary heart disease in patients with hypercholesterolemia. Report of the Program on the Surgical Control of the Hyperlipidemias (POSCH). N Engl J Med, 1990; 323: 946-955

7) Gragnano F and Calabro P: Role of dual lipid-lowering therapy in coronary atherosclerosis regression: Evidence from recent studies. Atherosclerosis, 2018; 269: 219-228 
8) Aikawa M, Rabkin E, Okada Y, Voglic SJ, Clinton SK, Brinckerhoff CE, Sukhova GK and Libby P: Lipid lowering by diet reduces matrix metalloproteinase activity and increases collagen content of rabbit atheroma: a potential mechanism of lesion stabilization. Circulation, 1998; 97: 2433-2444

9) Badimon JJ, Badimon L and Fuster V: Regression of atherosclerotic lesions by high density lipoprotein plasma fraction in the cholesterol-fed rabbit. J Clin Invest, 1990; 85: 1234-1241

10) Brown BG, Zhao XQ, Sacco DE and Albers JJ: Lipid lowering and plaque regression. New insights into prevention of plaque disruption and clinical events in coronary disease. Circulation, 1993; 87: 1781-1791

11) Feig JE: Regression of atherosclerosis: insights from animal and clinical studies. Ann Glob Health, 2014; 80: 13-23

12) Farmer JA and Gotto AM, Jr.: Dyslipidemia and the vulnerable plaque. Progress in cardiovascular diseases, 2002; 44: $415-428$

13) Bang HO and Dyerberg J: Personal reflections on the incidence of ischaemic heart disease in Oslo during the Second World War. Acta Med Scand, 1981; 210: 245-248

14) Blankenhorn DH, Nessim SA, Johnson RL, Sanmarco ME, Azen SP and Cashin-Hemphill L: Beneficial effects of combined colestipol-niacin therapy on coronary atherosclerosis and coronary venous bypass grafts. Jama, 1987; 257: 3233-3240

15) Brown G, Albers JJ, Fisher LD, Schaefer SM, Lin JT, Kaplan C, Zhao XQ, Bisson BD, Fitzpatrick VF and Dodge HT: Regression of coronary artery disease as a result of intensive lipid-lowering therapy in men with high levels of apolipoprotein B. N Engl J Med, 1990; 323: $1289-1298$

16) Crisby M, Nordin-Fredriksson G, Shah PK, Yano J, Zhu $\mathrm{J}$ and Nilsson J: Pravastatin treatment increases collagen content and decreases lipid content, inflammation, metalloproteinases, and cell death in human carotid plaques: implications for plaque stabilization. Circulation, 2001; 103: 926-933

17) Kane JP, Malloy MJ, Ports TA, Phillips NR, Diehl JC and Havel RJ: Regression of coronary atherosclerosis during treatment of familial hypercholesterolemia with combined drug regimens. Jama, 1990; 264: 3007-3012

18) Mintz GS, Nissen SE, Anderson WD, Bailey SR, Erbel R, Fitzgerald PJ, Pinto FJ, Rosenfield K, Siegel RJ, Tuzcu EM and Yock PG: American College of Cardiology Clinical Expert Consensus Document on Standards for Acquisition, Measurement and Reporting of Intravascular Ultrasound Studies (IVUS). A report of the American College of Cardiology Task Force on Clinical Expert Consensus Documents. Journal of the American College of Cardiology, 2001; 37: 1478-1492

19) Gogas BD, Faroog V, Serruys PW and Garcia-Garcia HM: Assessment of coronary atherosclerosis by IVUS and IVUS-based imaging modalities: progression and regression studies, tissue composition and beyond. The international journal of cardiovascular imaging, 2011; 27: 225237

20) Garcia-Garcia HM, Gogas BD, Serruys PW and Bruining $\mathrm{N}$ : IVUS-based imaging modalities for tissue characteriza- tion: similarities and differences. The international journal of cardiovascular imaging, 2011; 27: 215-224

21) Takagi T, Yoshida K, Akasaka T, Hozumi T, Morioka $S$ and Yoshikawa J: Intravascular ultrasound analysis of reduction in progression of coronary narrowing by treatment with pravastatin. Am J Cardiol, 1997; 79: 16731676

22) Matsuzaki M, Hiramori K, Imaizumi T, Kitabatake A, Hishida H, Nomura M, Fujii T, Sakuma I, Fukami K, Honda $\mathrm{T}$, Ogawa $\mathrm{H}$ and Yamagishi $\mathrm{M}$ : Intravascular ultrasound evaluation of coronary plaque regression by low density lipoprotein-apheresis in familial hypercholesterolemia: the Low Density Lipoprotein-Apheresis Coronary Morphology and Reserve Trial (LACMART). Journal of the American College of Cardiology, 2002; 40: 220-227

23) Schartl M, Bocksch W, Koschyk DH, Voelker W, Karsch KR, Kreuzer J, Hausmann D, Beckmann S and Gross M: Use of intravascular ultrasound to compare effects of different strategies of lipid-lowering therapy on plaque volume and composition in patients with coronary artery disease. Circulation, 2001; 104: 387-392

24) Nissen SE, Tuzcu EM, Schoenhagen P, Brown BG, Ganz P, Vogel RA, Crowe T, Howard G, Cooper CJ, Brodie B, Grines CL, DeMaria AN and Investigators R: Effect of intensive compared with moderate lipid-lowering therapy on progression of coronary atherosclerosis: a randomized controlled trial. Jama, 2004; 291: 1071-1080

25) Nissen SE, Nicholls SJ, Sipahi I, Libby P, Raichlen JS, Ballantyne CM, Davignon J, Erbel R, Fruchart JC, Tardif JC, Schoenhagen P, Crowe T, Cain V, Wolski K, Goormastic M, Tuzcu EM and Investigators A: Effect of very high-intensity statin therapy on regression of coronary atherosclerosis: the ASTEROID trial. Jama, 2006; 295: 1556-1565

26) Okazaki S, Yokoyama T, Miyauchi K, Shimada K, Kurata T, Sato $\mathrm{H}$ and Daida H: Early statin treatment in patients with acute coronary syndrome: demonstration of the beneficial effect on atherosclerotic lesions by serial volumetric intravascular ultrasound analysis during half a year after coronary event: the ESTABLISH Study. Circulation, 2004; 110: 1061-1068

27) Hiro T, Kimura T, Morimoto T, Miyauchi K, Nakagawa Y, Yamagishi M, Ozaki Y, Kimura K, Saito S, Yamaguchi T, Daida H, Matsuzaki M and Investigators J-A: Effect of intensive statin therapy on regression of coronary atherosclerosis in patients with acute coronary syndrome: a multicenter randomized trial evaluated by volumetric intravascular ultrasound using pitavastatin versus atorvastatin (JAPAN-ACS [Japan assessment of pitavastatin and atorvastatin in acute coronary syndrome] study). Journal of the American College of Cardiology, 2009; 54: 293-302

28) Takayama T, Hiro T, Yamagishi M, Daida H, Hirayama A, Saito S, Yamaguchi T, Matsuzaki M and Investigators C: Effect of rosuvastatin on coronary atheroma in stable coronary artery disease: multicenter coronary atherosclerosis study measuring effects of rosuvastatin using intravascular ultrasound in Japanese subjects (COSMOS). Circ J, 2009; 73: 2110-2117

29) Nicholls SJ, Ballantyne CM, Barter PJ, Chapman MJ, Erbel RM, Libby P, Raichlen JS, Uno K, Borgman M, 
Wolski K and Nissen SE: Effect of two intensive statin regimens on progression of coronary disease. $\mathrm{N}$ Engl J Med, 2011; 365: 2078-2087

30) Tsujita K, Sugiyama S, Sumida H, Shimomura H, Yamashita T, Yamanaga K, Komura N, Sakamoto K, Oka H, Nakao K, Nakamura S, Ishihara M, Matsui K, Sakaino N, Nakamura N, Yamamoto N, Koide S, Matsumura T, Fujimoto K, Tsunoda R, Morikami Y, Matsuyama K, Oshima S, Kaikita K, Hokimoto S, Ogawa H and Investigators P-I: Impact of Dual Lipid-Lowering Strategy With Ezetimibe and Atorvastatin on Coronary Plaque Regression in Patients With Percutaneous Coronary Intervention: The Multicenter Randomized Controlled PRECISEIVUS Trial. Journal of the American College of Cardiology, 2015; 66: 495-507

31) Nicholls SJ, Puri R, Anderson T, Ballantyne CM, Cho L, Kastelein JJ, Koenig W, Somaratne R, Kassahun H, Yang J, Wasserman SM, Scott R, Ungi I, Podolec J, Ophuis $\mathrm{AO}$, Cornel JH, Borgman M, Brennan DM and Nissen SE: Effect of Evolocumab on Progression of Coronary Disease in Statin-Treated Patients: The GLAGOV Randomized Clinical Trial. Jama, 2016; 316: 2373-2384

32) Kolodgie FD, Burke AP, Farb A, Gold HK, Yuan J, Narula J, Finn AV and Virmani R: The thin-cap fibroatheroma: a type of vulnerable plaque: the major precursor lesion to acute coronary syndromes. Curr Opin Cardiol, 2001; 16: 285-292

33) Verhoeven BA, Moll FL, Koekkoek JA, van der Wal AC, de Kleijn DP, de Vries JP, Verheijen JH, Velema E, Busser E, Schoneveld A, Virmani R and Pasterkamp G: Statin treatment is not associated with consistent alterations in inflammatory status of carotid atherosclerotic plaques: a retrospective study in 378 patients undergoing carotid endarterectomy. Stroke; a journal of cerebral circulation, 2006; 37: 2054-2060

34) Hartung D, Sarai M, Petrov A, Kolodgie F, Narula N, Verjans J, Virmani R, Reutelingsperger C, Hofstra L and Narula J: Resolution of apoptosis in atherosclerotic plaque by dietary modification and statin therapy. J Nucl Med, 2005; 46: 2051-2056

35) Kawasaki M, Sano K, Okubo M, Yokoyama H, Ito Y, Murata I, Tsuchiya K, Minatoguchi S, Zhou X, Fujita H and Fujiwara $\mathrm{H}$ : Volumetric quantitative analysis of tissue characteristics of coronary plaques after statin therapy using three-dimensional integrated backscatter intravascular ultrasound. Journal of the American College of Cardiology, 2005; 45: 1946-1953

36) Nasu K, Tsuchikane E, Katoh O, Tanaka N, Kimura M, Ehara M, Kinoshita Y, Matsubara T, Matsuo H, Asakura K, Asakura Y, Terashima M, Takayama T, Honye J, Hirayama A, Saito S and Suzuki T: Effect of fluvastatin on progression of coronary atherosclerotic plaque evaluated by virtual histology intravascular ultrasound. JACC Cardiovascular interventions, 2009; 2: 689-696

37) Park SJ, Kang SJ, Ahn JM, Chang M, Yun SC, Roh JH, Lee PH, Park HW, Yoon SH, Park DW, Lee SW, Kim YH, Lee CW, Mintz GS, Han KH and Park SW: Effect of Statin Treatment on Modifying Plaque Composition: A Double-Blind, Randomized Study. Journal of the American College of Cardiology, 2016; 67: 1772-1783

38) Yokoyama M, Komiyama N, Courtney BK, Nakayama T,
Namikawa S, Kuriyama N, Koizumi T, Nameki M, Fitzgerald PJ and Komuro I: Plasma low-density lipoprotein reduction and structural effects on coronary atherosclerotic plaques by atorvastatin as clinically assessed with intravascular ultrasound radio-frequency signal analysis: a randomized prospective study. Am Heart J, 2005; 150: 287

39) Hong MK, Park DW, Lee CW, Lee SW, Kim YH, Kang DH, Song JK, Kim JJ, Park SW and Park SJ: Effects of statin treatments on coronary plaques assessed by volumetric virtual histology intravascular ultrasound analysis. JACC Cardiovascular interventions, 2009; 2: 679-688

40) Toi T, Taguchi I, Yoneda S, Kageyama M, Kikuchi A, Tokura M, Kanaya T, Abe S, Matsuda R and Kaneko N: Early effect of lipid-lowering therapy with pitavastatin on regression of coronary atherosclerotic plaque. Comparison with atorvastatin. Circ J, 2009; 73: 1466-1472

41) Nozue $T$, Yamamoto $S$, Tohyama $S$, Umezawa $S$, Kunishima T, Sato A, Miyake S, Takeyama Y, Morino Y, Yamauchi T, Muramatsu T, Hibi K, Sozu T, Terashima M and Michishita I: Statin treatment for coronary artery plaque composition based on intravascular ultrasound radiofrequency data analysis. Am Heart J, 2012; 163: 191-199 e191

42) Lee SW, Hau WK, Kong SL, Chan KK, Chan PH, Lam SC, Tam FC, Wong MK, Chan CW, Lam YM, Tse HF and Chan RH: Virtual histology findings and effects of varying doses of atorvastatin on coronary plaque volume and composition in statin-naive patients: the VENUS study. Circ J, 2012; 76: 2662-2672

43) Hattori K, Ozaki Y, Ismail TF, Okumura M, Naruse H, Kan S, Ishikawa M, Kawai T, Ohta M, Kawai H, Hashimoto T, Takagi Y, Ishii J, Serruys PW and Narula J: Impact of statin therapy on plaque characteristics as assessed by serial OCT, grayscale and integrated backscatter-IVUS. JACC Cardiovasc Imaging, 2012; 5: 16-177

44) Nicholls SJ, Hsu A, Wolski K, Hu B, Bayturan O, Lavoie A, Uno K, Tuzcu EM and Nissen SE: Intravascular ultrasound-derived measures of coronary atherosclerotic plaque burden and clinical outcome. Journal of the American College of Cardiology, 2010; 55: 2399-2407

45) Dohi T, Miyauchi K, Okazaki S, Yokoyama T, Yanagisawa N, Tamura H, Kojima T, Yokoyama K, Kurata T and Daida H: Plaque regression determined by intravascular ultrasound predicts long-term outcomes of patients with acute coronary syndrome. J Atheroscler Thromb, 2011; 18: 231-239

46) Cannon CP, Blazing MA, Giugliano RP, McCagg A, White JA, Theroux P, Darius H, Lewis BS, Ophuis TO, Jukema JW, De Ferrari GM, Ruzyllo W, De Lucca P, Im K, Bohula EA, Reist C, Wiviott SD, Tershakovec AM, Musliner TA, Braunwald E, Califf RM and Investigators I-I: Ezetimibe Added to Statin Therapy after Acute Coronary Syndromes. N Engl J Med, 2015; 372: 2387-2397

47) Sabatine MS, Giugliano RP, Keech AC, Honarpour N, Wiviott SD, Murphy SA, Kuder JF, Wang H, Liu T, Wasserman SM, Sever PS, Pedersen TR, Committee FS and Investigators: Evolocumab and Clinical Outcomes in Patients with Cardiovascular Disease. N Engl J Med, 2017; 376: 1713-1722

48) Chistiakov DA, Myasoedova VA, Revin VV, Orekhov AN 
and Bobryshev YV: The phenomenon of atherosclerosis reversal and regression: Lessons from animal models. Exp Mol Pathol, 2017; 102: 138-145

49) Nakajima N, Miyauchi K, Yokoyama T, Ogita M, Miyazaki T, Tamura H, Nishino A, Yokoyama K, Okazaki
S, Kurata T, Suwa S, Daida H: Effect of combination of ezetimibe and a statin on coronary plaque regression in patients with acute coronary syndrome: ZEUS trial (eZEtimibe Ultrasound Study). IJC Metabolic \& Endocrine, 2014; 3: 8-13 